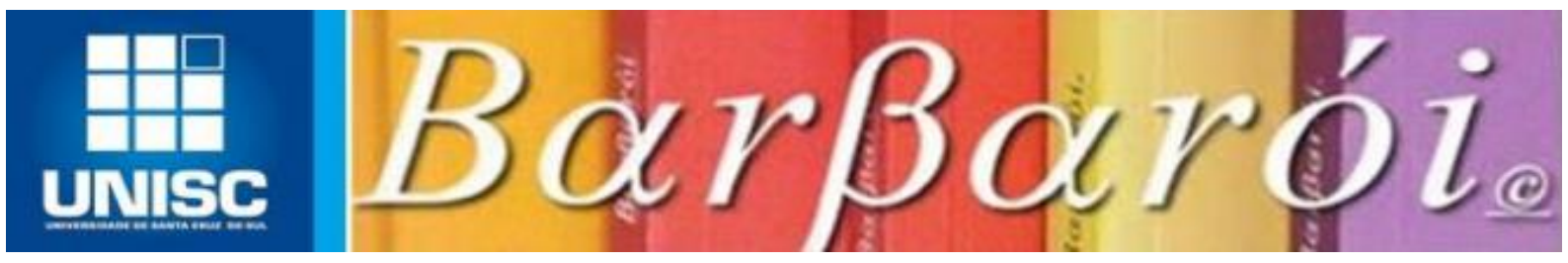

\title{
BRASILIANAS MAQUIAVÉLICAS
}

\section{DOI: http://dx.doi.org/10.17058/barbaroi.v51i1.12472}

\author{
Luiz Maurício Bentim da Rocha Menezes \\ Instituto Federal do triângulo mineiro - IFTM - Brasil \\ Gabriel Medeiros Chati \\ Universidade Federal do Pampa - UNIPAMPA - Brasil
}

\section{RESUMO}

Maquiavel ao falar do principado civil, em sua obra $O$ Príncipe, irá diferenciar dois tipos de governo possíveis: aquele cujo príncipe se apoia nos muitos (povo) e aquele cujo príncipe se apoia nos poucos (oligarcas). Dessa forma, o que ele tem em mente é identificar os dois tipos possíveis de principados civis e demonstrar que ambos conseguem chegar ao poder se se utilizarem dos meios adequados. Este artigo tem o intuito de investigar os Governos Lula e Temer sob a ótica maquiaveliana, demonstrando de que maneira a divisão de Maquiavel pode ser verificada nesses governos através de análise de dados e avaliando a capacidade política dos respectivos governantes.

PALAVRAS-CHAVE: Brasil. Maquiavel. Governo Lula. Governo Temer.

\section{Introdução}

As formas de governo quando estudadas dentro da ótica da filosofia política são tratadas basicamente de duas maneiras: (i) de maneira descritiva, descrevendo cada uma delas e dizendo em que se diferenciam; e (ii) de maneira prescritiva, onde se analisa qual é a melhor e se faz uma hierarquia dos valores de cada uma. A descrição de uma forma de governo vai possibilitar conhecê-la detalhadamente, podendo ainda ser comparada historicamente, dizendo-se como cada uma delas ocorre em diferentes épocas. A prescrição envolve um estudo minucioso dos valores envolvidos ao tratar de suas características. Em sua obra $O$ Príncipe, Maquiavel está preocupado tanto em descrever a maneira pela qual alguns homens se destacaram e chegaram ao poder, como também em prescrever de que maneira um príncipe deve agir para chegar ao poder e, principalmente, manter o seu governo. Entretanto, a prescrição maquiaveliana não é quanto ao melhor tipo de governante, mas quanto ao que deve fazer aquele que deseja conquistar um Estado. Dessa maneira, todas as formas de governo são legítimas se o príncipe conseguir se manter no poder e, para isso, há diferentes possibilidades. 
Maquiavel viveu no período do renascimento italiano, marcado pela forte disputa de poder entre os condottieri, senhores da nobreza que controlavam milícias e, assim, desejavam superar os demais. Como segundo secretário da cidade de Florença, Maquiavel vivenciou muito dessa experiência política das disputas territoriais, do uso da violência e do engano para conseguir conquistar o poder. Viroli nos conta uma anedota interessante sobre um sonho que Maquiavel teria tido momentos antes da sua morte em 21 de junho de 1527:

\begin{abstract}
Disse ter visto um grupo de homens malvestidos, de aparência miserável e sofredora. Ao indagar quem eram, recebeu a seguinte resposta: 'somos os santos e os bemaventurados, vamos para o Paraíso'. Em seguida, avistou uma multidão de homens de nobre e grave aspecto, vestidos com roupas majestosas, que discutiam solenemente sobre importantes problemas políticos. Reconheceu os grandes filósofos e historiadores da Antiguidade que haviam escrito obras fundamentais sobre política e sobre os Estados, entre os quais Platão, Plutarco e Tácito. Perguntou também a eles quem eram e para onde se dirigiam: 'somos os condenados ao Inferno', responderam. Maquiavel termina seu relato explicando aos amigos que queria antes ir para o inferno discutir sobre política com os grandes homens da Antiguidade do que ser mandado ao paraíso, para morrer de tédio na companhia dos beatos e dos santos. (VIROLI, 2002, p. 17)
\end{abstract}

Tal anedota acabou ficando conhecida nos séculos vindouros como o sonho de Maquiavel e caracteriza bem a escolha de Maquiavel pelas coisas grandes da política. No capítulo 9 do Príncipe, Maquiavel se propõe a falar do principado civil e as maneiras pelas quais esse principado é estabelecido. Isso o levará a dividir o principado civil em dois tipos possíveis: aquele cujo príncipe se apoia nos muitos (povo) e aquele cujo príncipe se apoia nos poucos (oligarcas). O primeiro seria descrito como aquele cujo príncipe consegue atingir o poder com a ajuda da maioria, tendo essa ao seu lado pronta para lutar por ele. O segundo é quando o príncipe consegue fazer uma aliança com a oligarquia local e, com a ajuda desta, consegue alcançar o controle do Estado. Ambas as formas são bem vistas se o fim de se alcançar o governo for bem-sucedida. Dessa forma, o que ele tem em mente, ao escrever esse capítulo, é identificar os dois tipos possíveis de principados civis e demonstrar que tanto o governante dos muitos, como o governante dos poucos consegue chegar ao poder se eles se utilizarem dos meios adequados para isso.

Nesse artigo, pretendemos tratar do caso brasileiro tomando como fio condutor a interpretação maquiaveliana sobre o principado civil. Mais especificamente iremos avaliar o Governo Lula e o Governo Temer, entendendo que o primeiro presidente teria alcançado o poder apoiado, principalmente, no povo e o segundo presidente apoiado na oligarquia do país, representada pelo empresariado industrial e rentistas do mercado financeiro. Desse modo, o que buscamos aqui não é uma diferença qualitativa das medidas tomadas por eles para conseguirem o governo, nem dizer se um governo é melhor do que o outro. Nosso intuito consiste em analisar 
as consequências de cada um dos governos se tomarmos como diferença específica a maneira pela qual se atingiu o poder:

porque os grandes, vendo que não podem resistir ao povo, começam a dirigir a reputação para um deles e fazem-no príncipe a fim de poderem, à sua sombra, saciar o apetite deles; o povo também, vendo que não pode resistir aos grandes, dirige a reputação para um só e o faz príncipe, para ser defendido pela sua autoridade. ${ }^{1}$

Maquiavel ao escrever o Príncipe toma uma nova posição com relação a maneira de se lidar com o poder e o governo do Estado. Como o Estado está centrado na figura do príncipe, é preciso que ele permaneça o máximo possível no poder, pois, do contrário, o próprio Estado se torna instável e prejudicial para os cidadãos. Dessa forma, Maquiavel não está preocupado em como deveria agir um governante em sua forma ideal, mas considera "mais conveniente ir atrás da verdade efetiva da coisa [verità effetuale della cosa] do que da sua imaginação [immaginazione di epsa]" (Príncipe, p. 183). Portanto, irá se abster de qualquer tipo de formação de governo, de qual o tipo de governante se deve ter ou como moralmente este deve ser, mas irá se prender apenas em como deve agir um governante em determinadas situações para que assim conquiste e/ou mantenha o poder político, pois "o tema do livro é o príncipe, mais especialmente o novo príncipe" (STRAUSS, 2015, p. 91). Tomando as palavras de Maquiavel como a premissa inicial de nosso trabalho, iremos verificar juntos aos dois governantes brasileiros que medidas eles tomaram para se apoderar do governo do Brasil e que tipo de consequências isso trouxe para os seus governados. Para concretizar isso, utilizaremos alguns dados sobre a composição e execução do orçamento público, com enfoque nos recursos da Assistência Social, dados mais conjunturais que nos indicarão o nível de emprego formal e a evolução da renda, e dados sobre o desempenho dos bancos, mais especificamente seus lucros, analisando o período que antecede o primeiro mandato de Lula (2003) até o governo Temer (2017) sempre que possível. Nosso intuito é demonstrar que há uma analogia possível entre a proposta maquiaveliana e os tipos de governo adotados pelos presidentes do Brasil.

Quanto à escolha dos dados e seu manuseio, é importante destacar que (i) o conjunto escolhido não pretende ser exaustivo, mas sim ilustrativo, portanto, servem de base para a análise principal, qual seja, a do comportamento dos governantes na definição de suas estratégias, identificação de aliados, apoiadores e detratores, mas não esgotam nem substituem outros conjuntos de dados como os macroeconômicos, os indicadores externos de

\footnotetext{
${ }^{1}$ Maquiavel, N. O Príncipe. Tradução de Diogo Pires Aurélio. São Paulo: Editora 34, 2017, p. 147. Demais citações à obra serão abreviadas por "Príncipe".
} 
desenvolvimento - tais como o Índice de Desenvolvimento Humano ou Coeficiente de Gini ou mesmo a análise de outras políticas públicas como as de Educação, Saúde ou Saneamento Básico, por exemplo; e (ii) é evidente que os dados mais consolidados se referem ao período Lula e, nesse sentido, é mais fácil fazer a análise de seu desempenho e decisões tomadas justamente por esse distanciamento no tempo, coisa que não se observa em relação às possibilidades de análise do período Temer; isso não quer dizer que não possamos, como nos dispusemos, procurar tendências, padrões e eventuais mudanças de rumos nestes governos, a partir dos dados observados durante todo período proposto.

Contudo, antes de entrarmos propriamente nos dados, vamos observar a maneira como cada um dos presidentes chegou ao poder. Luiz Inácio Lula da Silva foi eleito e reeleito, governando o país de 01 de janeiro de 2003 até 31 de dezembro de 2010. Ao final do seu governo seu índice de popularidade estava acima dos $80 \%$, o que demonstra a aceitação em grande parte do seu programa de governo pelo povo e, também, das suas escolhas enquanto governante. Michel Miguel Elias Temer Lulia não foi eleito como presidente, mas compunha, como vice-presidente, a chapa da presidente eleita Dilma Rousseff. Após a cassação do mandato presidencial de Dilma Rousseff nos términos do processo de Impeachment, Michel Temer foi empossado presidente do Brasil em 31 de agosto de 2016 e será o presidente até 31 de dezembro de 2018. O índice de popularidade de Michel Temer está em torno de 9\% e seu índice de rejeição está acima de 70\%, segundo pesquisa do Ibope realizada em março de 2018. No entanto, Temer teve grande apoio do empresariado brasileiro para chegar ao poder, a Federação das Industrias do Estado de São Paulo (Fiesp), por exemplo, teve grande participação nas manifestações ${ }^{2}$ que pediram o impeachment da presidente Dilma Rousseff.

O quadro apresentado entre os dois presidentes já demonstra uma diferença específica quanto à forma de ascensão ao poder: um foi eleito pelo voto popular, o outro colocado no poder devido a um impeachment; um teve aprovação popular devido ao desenvolvimento de programas sociais, o outro teve aprovação do empresariado para implementar reformas que desagradavam a maioria da população. Ao observarmos essa diferença podemos perceber o motivo pelo qual, apesar de ambos comporem um principado civil, nas palavras de Maquiavel,

\footnotetext{
2 "As Jornadas de Junho" de 2013 tiveram como estopim o aumento da tarifa de transporte público na cidade de São Paulo com ampla adesão de trabalhadores diretamente afetados. Entretanto, destacamos o caráter plural e diversificado de demandas que podem ser associadas à série de manifestações que sucederam. Observa-se que, com a adesão de veículos de comunicação que passam a apoiar o movimento, elas se tornaram mais massivas e fica notória a nova narrativa da imprensa de que tais manifestações seriam "sem líderes, e sem partidos políticos". Isso abriu espaço para agentes "não-políticos", ou melhor, organizações que não fossem partidos políticos, a exemplo da FIESP. Seu famoso Pato Amarelo fixado à frente de sua sede na Avenida Paulista foi testemunha por diversas vezes da entoação emocionada do Hino Nacional cantado por milhares de "patriotas" devidamente fardados com a camisa oficial da seleção brasileira.
} 
um teria o apoio dos muitos e o outro o apoio dos poucos. Dito isso, passemos às análises mais pormenorizadas de cada um dos tipos de governo estabelecidos no principado civil junto a cada governante que compõe esses governos.

\section{0 governo dos muitos}

O governo Lula é o governo estabelecido após a vitória do presidenciável Luiz Inácio Lula da Silva. Lula foi eleito com ampla maioria de votos o que indica uma grande força popular. Entretanto, apesar do governo Lula ser visto em grande parte como um governo popular, ele não realizou de modo algum uma ruptura com os interesses do mercado financeiro. O que Lula fez foi estabelecer um acordo com o empresariado local para garantir sua vitória nas eleições para presidente ${ }^{3}$. Esse acordo pode ser visto como uma grande articulação política que visava tranquilizar os interesses de Mercado e, assim, evitar resistências que poderiam levalo a uma quarta derrota.

Lula sabia que a política é a arte do compromisso, das concessões mútuas, para alcançar maioria; mais do que isso, ele sabia que é possível ser eleito sem o apoio da burguesia, mas é impossível governar sem ela. Por isso, já em um famoso documento de sua campanha eleitoral de 2002, a 'Carta ao povo brasileiro', ele mudou o tom e o conteúdo de suas propostas, e assim que foi eleito, demonstrou que sabia que não é possível governar o capitalismo sem os capitalistas e logrou deles se aproximar. (BRESSER-PEREIRA, 2016, p. 353)

Isso efetivamente garantiu a eleição de Lula e o estabelecimento de seu governo, podendo ser visto como um pensamento político arguto para se conseguir chegar ao poder, pois acalmava a elite ao mesmo tempo em que se apoiava no povo para chegar ao governo. Por isso, devemos atentar que, apesar da manobra utilizada ser algo que aproxima Lula dos poucos, seus desempenhos anteriores (fora segundo nas três disputas, chegando a uma média de primeiro turno de $25,32 \%$ ) fazem com que ele seja alavancado a presidente pelas massas e ele irá se apoiar nelas para vencer, pois

aquele que chega ao principado com o apoio popular vê-se lá sozinho e à sua volta ou não tem ninguém, ou tem pouquíssimos que não estejam prontos a obedecer. Além disso, não se pode satisfazer os grandes com honestidade e sem injúria para outros, mas o povo sim: porque a finalidade do povo é mais honesta que a dos grandes, querendo estes oprimir e aquele não ser oprimido. (Príncipe, p. 147-9)

\footnotetext{
${ }^{3}$ Exemplos dessa disposição de incluir os interesses do empresariado em seu programa de governo são (i) a presença na chapa presidencial de um grande empresário do ramo têxtil, José de Alencar do Partido Liberal e, (ii) a "Carta aos brasileiros" que, com seu forte teor reformista, acabou apaziguando os ânimos dos mercados de capitais.
} 
Lula teve desempenho eleitoral significativo, elegeu-se para o primeiro mandato com mais de $60 \%$ dos votos no segundo turno e soube, como poucos presidentes do Brasil, ganhar as massas a seu favor. Podemos até mesmo dizer que ele tem seu poder político legitimado pelo seu carisma, para usarmos o sentido weberiano de legitimação de poder. Soube ainda aproveitar esse carisma para ter os muitos favoráveis ao seu governo enquanto negociava sua política econômica com a oligarquia, em espécie de jogo dual que incluía interesses muitas vezes tidos como antagônicos e inconciliáveis.

No que se refere aos mandatos propriamente e suas iniciativas frente ao poder máximo da República brasileira, Lula elegeu como carro chefe o desenvolvimento de programas sociais, organizando, unificando e dando mais robustez a iniciativas que já existiam nos governos "socialdemocratas" tucanos ${ }^{4}$.

Não buscamos aqui aferir necessariamente a efetividade de programas de transferência direta de renda, a exemplo do Bolsa Família, ou ainda programas de moradia subsidiada, a exemplo do Minha Casa Minha Vida (MCMV). Em linhas gerais, sob uma perspectiva de análise do orçamento público, pode-se dizer que o governo Lula deu à Assistência Social um lugar de destaque. Potencialmente apoiado na ideia de que, ao incluir diretamente amplas camadas da população nestes programas, as tensões sociais tendem a diminuir, Lula tem como saldo desta política sua ainda presente identificação como um governante que fez muito pelos mais pobres. Segundo Bresser-Pereira (2016, p. 358),

os números relativos à diminuição da desigualdade e à melhoria dos padrões de vida da classe trabalhadora desde a transição democrática e, em particular, no governo Lula, foram impressionantes. A desigualdade já vinha diminuindo em função do aumento das despesas sociais em educação, saúde e em programas focados de assistência social, mas houve aceleração nítida no governo Lula em função do aumento do salário mínimo real e do aumento das despesas de assistência social. Segundo o Banco Mundial, o Brasil conseguiu praticamente eliminar a pobreza extrema e fez isso mais rápido que seus vizinhos.

Mesmo que haja controvérsia quanto à sustentabilidade financeira das políticas sociais de Lula, sua motivação e alcance, não há dúvida quanto ao seu impacto na economia. Estudos acerca do MCMV indicam um caráter dual "reduzir o déficit habitacional do país e aquecer a

\footnotetext{
${ }^{4}$ O próprio texto da lei no 10.836 , de 9 de janeiro de 2004, que cria o Bolsa Família, destaca que sua finalidade é "a unificação dos procedimentos de gestão e execução das ações de transferência de renda do Governo Federal, especialmente as do Programa Nacional de Renda Mínima vinculado à Educação - Bolsa Escola, instituído pela Lei ${ }^{\circ}$ 10.219, de 11 de abril de 2001, do Programa Nacional de Acesso à Alimentação - PNAA, criado pela Lei n o 10.689, de 13 de junho de 2003, do Programa Nacional de Renda Mínima vinculada à Saúde - Bolsa Alimentação, instituído pela Medida Provisória n o 2.206-1, de 6 de setembro de 2001, do Programa Auxílio-Gás, instituído pelo Decreto $\mathrm{n}^{\circ} 4.102$, de 24 de janeiro de 2002, e do Cadastramento Único do Governo Federal, instituído pelo Decreto $\mathrm{n}^{\mathrm{o}}$ 3.877, de 24 de julho de 2001". Disponível em: http://www.planalto.gov.br/ccivil_03/_ato20042006/2004/lei/110.836.htm. Consultado em: 21/07/2018.
} 
economia de forma anticíclica em ambiente de crise” (CONOF, 2017, p. 4). O ano de 2008, anterior à instituição do programa, fora um dos mais instáveis em âmbito mundial, inclusive com economias consideradas fortes tendo desempenhos negativos. Entretanto, o "tsunami” que partira dos EEUU e vinha varrendo mercados mundo afora, segundo declaração de Lula à época: "se chegar ao Brasil, será marolinha" (Galhardo, 2008). Assim, ao mesmo tempo que a equipe econômica de seu governo aplicava remédios em resposta à crise econômica global, o Príncipe dos desvalidos tinha mais uma iniciativa de impacto popular na sua já recheada vitrine.

Cabe, mesmo sem a pretensão de realizar análise minuciosa, estabelecermos uma leitura crítica do alcance de iniciativas como estas. Se tomarmos emprestada da economia política ferramentas para analisar tais programas, é possível indicar que esses não têm a "capacidade de desarmar os mecanismos estruturais de reprodução da pobreza" (FILGUEIRAS, 2007, p. 162). Justamente por não terem esta mudança mais profunda como objetivo, estes programas focados na assistência social acabam por "apenas maneja[r] a pobreza, pois mantém em permanente estado de insegurança, indigência e dependência o seu público alvo" (FILGUEIRAS, 2007, p. 162). No entanto, importa-nos mais considerar os impactos na percepção da população, em especial das mais vulneráveis e de menor renda, em relação a tais políticas de assistência social, elemento central para nossa análise. Dito de outra forma, justamente por conta destes programas, estabelece-se uma relação direta entre a opinião de parte significativa da população em relação ao desempenho, e consequente aprovação, do governo Lula.

\section{0 governo dos poucos}

O governo Temer é marcado por uma série de propostas de reformas que afetariam o trabalho, a previdência e os gastos primários como saúde e educação. Um exemplo disso seria a Emenda Constitucional n ${ }^{\circ} 95$ de 15/12/2016, antiga PEC-55 e antiga PEC-241, que instituiu um novo regime fiscal para o país. A EC 95, apresentada pelo governo Temer, estabelece o congelamento dos recursos financeiros previstos no orçamento da União por vinte anos, uma vez que, a partir do ano de 2017 até 2036, o orçamento de cada ano será definido como o do ano anterior corrigido apenas pela inflação do período. Cabe ao poder Executivo realizar contingenciamentos de despesas, caso os recursos financeiros para o ano não sejam suficientes para cobrir o orçamento aprovado no ano anterior. No entanto, cumpre destacar que esses contingenciamentos têm sido realizados, mas apenas no próprio poder executivo, responsável, por exemplo, pela saúde, educação e segurança e que tanto o poder Legislativo quanto o poder

Judiciário continuam a executar seus orçamentos normalmente, inclusive com aumento de 
remuneração (salários) bem acima da inflação, como se o país não passasse por uma grave crise financeira.

O congelamento por vinte anos das despesas primárias acabaria com todo investimento real em educação, saúde, previdência e assistência social, direcionando o grosso do orçamento para o pagamento da dívida pública. A dívida pública, de forma técnica é uma maneira de complementar o financiamento do Estado, o que não é um mal em si mesmo. No entanto, o esquema da EC 95 faz da dívida pública, que deveria servir para complementar os recursos em benefício de todos, um veículo para desviar recursos públicos em direção ao sistema financeiro através do pagamento interminável dos juros da dívida e que teria como principais benificiários os grandes bancos e rentistas (FATTORELLI, 2015). A EC 95 apresentada pelo governo Temer restringirá os programas de governo e a vontade do povo, expressa nas ruas e nas urnas, pelos próximos cinco mandatos presidenciais. Mesmo que a economia cresça e permita, e o Estado tenha capacidade para melhorar as condições de vida da sociedade, o teto imposto aos gastos sociais vai impedir esse avanço social e transferirá todo o ganho real para o pagamento dos juros intermináveis da dívida pública (VAZ, 2016).

Com relação a Educação, o art. 212 da Constituição determina que, anualmente, a União aplique em despesas com Manutenção e Desenvolvimento do Ensino (MDE), no mínimo 18\% da receita líquida de transferências (receita de impostos deduzida de transferências constitucionais a Estados e Municípios). No entanto, segundo o Estudo Técnico No 12/2016 da Consultoria de Orçamento e Fiscalização Financeira (CONOF) da Câmara dos Deputados, em uma projeção sobre os impactos, da então PEC 241, entre 2016 a 2025, demonstra que

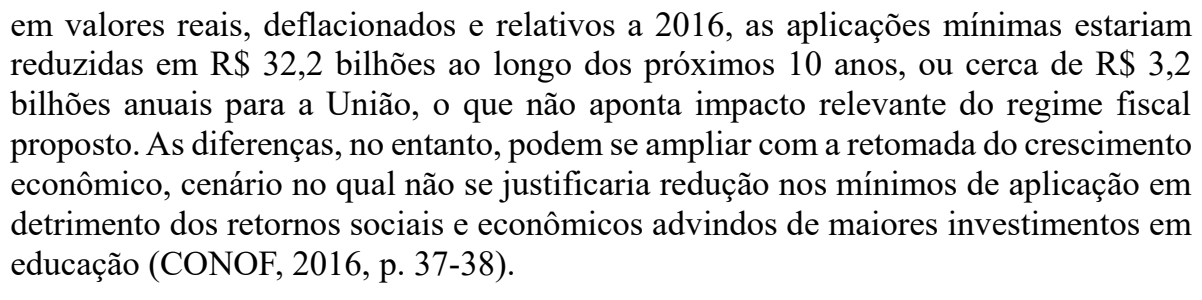

Desse modo, o impacto da EC 95 em longo prazo traz graves consequências para um desenvolvimento seguro de áreas básicas. Isso demonstra um interesse dos empresariados em tomar conta dessas áreas básicas sobre os cuidados da esfera pública. O que parece justificar a tática do governo Temer em beneficiar o Mercado e seus investidores ao invés de assegurar a confiança do povo em seu governo. Isso traz certas dificuldades, pois os grandes, em sua ganância, desejam sempre mais, enquanto o povo só deseja não ser oprimido. 
Aquele que acede ao principado com a ajuda dos grandes mantém-se com mais dificuldade do que aquele que se torna com a ajuda do povo, porque se vê príncipe com muitos à volta que lhe parecem ser seus iguais, e por isso não pode nem comandálos nem manobra-los a seu modo. (Príncipe, p. 147)

Maquiavel parece demonstrar com clareza que aquele que chega ao poder com a força dos poucos, acaba por ser por eles controlado ao invés de conseguir controla-los. E uma vez na mão dos grandes, difícil será de sair. Segundo David:

\begin{abstract}
As limitações do modelo e os efeitos adversos da austeridade fizeram o próprio FMI, famoso pela defesa que fazia dessas medidas, rever seu posicionamento e, no documento Fiscal Monitor de 2018, convocar os países a evitar políticas pró-cíclicas, como é o caso da EC 95, durante períodos de crise fiscal. O fundo argumenta que políticas contracíclicas poderiam produzir melhores resultados, por meio do investimento público em proteção social e infraestrutura, que poderiam ser financiados com tributação progressiva e pelo crescimento decorrente dos investimentos feitos, por causa dos efeitos multiplicadores dos investimentos sociais e da redistribuição de renda na economia nacional.

Definitivamente não é o que ocorre no Brasil nos dias de hoje. O cenário projetado é de piora social, ambiental e climática. A pobreza extrema, por exemplo, que diminuiu expressivos 75\% entre 2005 e 2015, com consequente saída do Brasil do Mapa da Fome em 2015, aumentou nos três anos de austeridade. $(2018$, p. 7)
\end{abstract}

Se concordarmos com David, perceberemos que o governo Temer claramente prefere beneficiar a elite do país do que o povo, de maneira que para que ele possa se sustentar no governo ele deve privilegiar aquela que o ajudou a chegar ao poder. Dessa forma, o governo Temer se encaixa com perfeição na descrição de Maquiavel do governo dos poucos, cujo o governante se apoia na elite local para poder governar.

\title{
3 A sagacidade de Lula (ou como o Príncipe conseguiu agradar a todos)
}

O projeto de conciliação de interesses de Lula logrou à manutenção do stato del príncipe de maneira singular: enquanto colocava os muitos no centro de diversas das iniciativas governamentais, mesmo mantendo-os na condição de objeto das políticas sociais, soube conter a ganância dos poucos, dando-lhes seu quinhão. Dessa forma, enquanto os muitos se agraciavam da melhora social e econômica, os poucos continuavam a ganhar como sempre fizeram como pretendemos demonstrar.

Um dado objetivo relativo à centralidade das políticas sociais e dos programas focalizados de combate à pobreza, encontra-se na composição do orçamento público executado pelo Governo Central ao longo dos anos Lula. A participação crescente da função Assistência Social é reflexo desta escolha: 


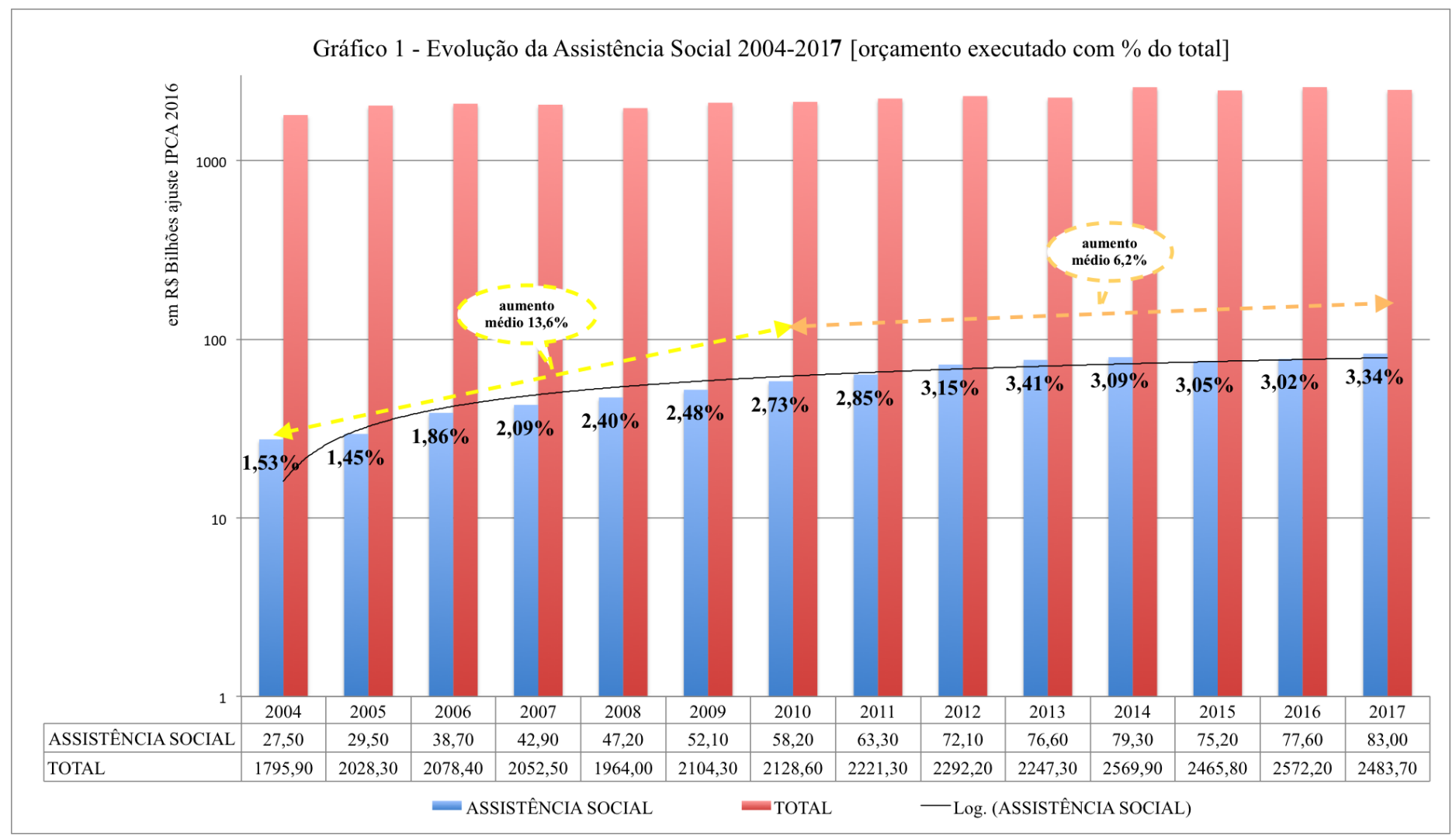

Fontes: Câmara dos Deputados, Orçamento da União em Foco n⿳01/2017; Sistema Integrado de Planejamento e Orçamento. Compilação própria.

Os recursos destinados à função Assistência Social cresceu significativamente a partir de 2006 , quando chegou a $1,86 \%$ do total dos gastos do governo federal, um aumento de $31,2 \%$ em comparação ao ano anterior. Mesmo que se perceba a manutenção da tendência de aumento por todo o período, importante notar que o crescimento foi muito mais acelerado no período que vai de 2004 a 2010, anos em que a definição da proposta de orçamento anual foi do governo de Lula. Neste período, a média anual é superior a 13\% contra 6\% entre 2011 e 2017 e a função Assistência Social, para exemplificar sua relevância na composição do orçamento, ficou à frente dos recursos destinados à Educação, salvo no ano de 2010. Assim, ao destinar parte significativa do orçamento para sustentar tais políticas, Lula se candidata a novo "pai dos pobres" e é aclamado ao brado popular com grande veemência.

Para explicar a percepção de bom desempenho dos governos Lula é relevante tomar os níveis de emprego e a renda como outro parâmetro. Para tal, nos utilizamos de dados referentes ao emprego formal, presentes no Cadastro Geral de Empregados e Desempregados (CAGED), e na Relação Anual de Informações Salariais (RAIS), respectivamente: 


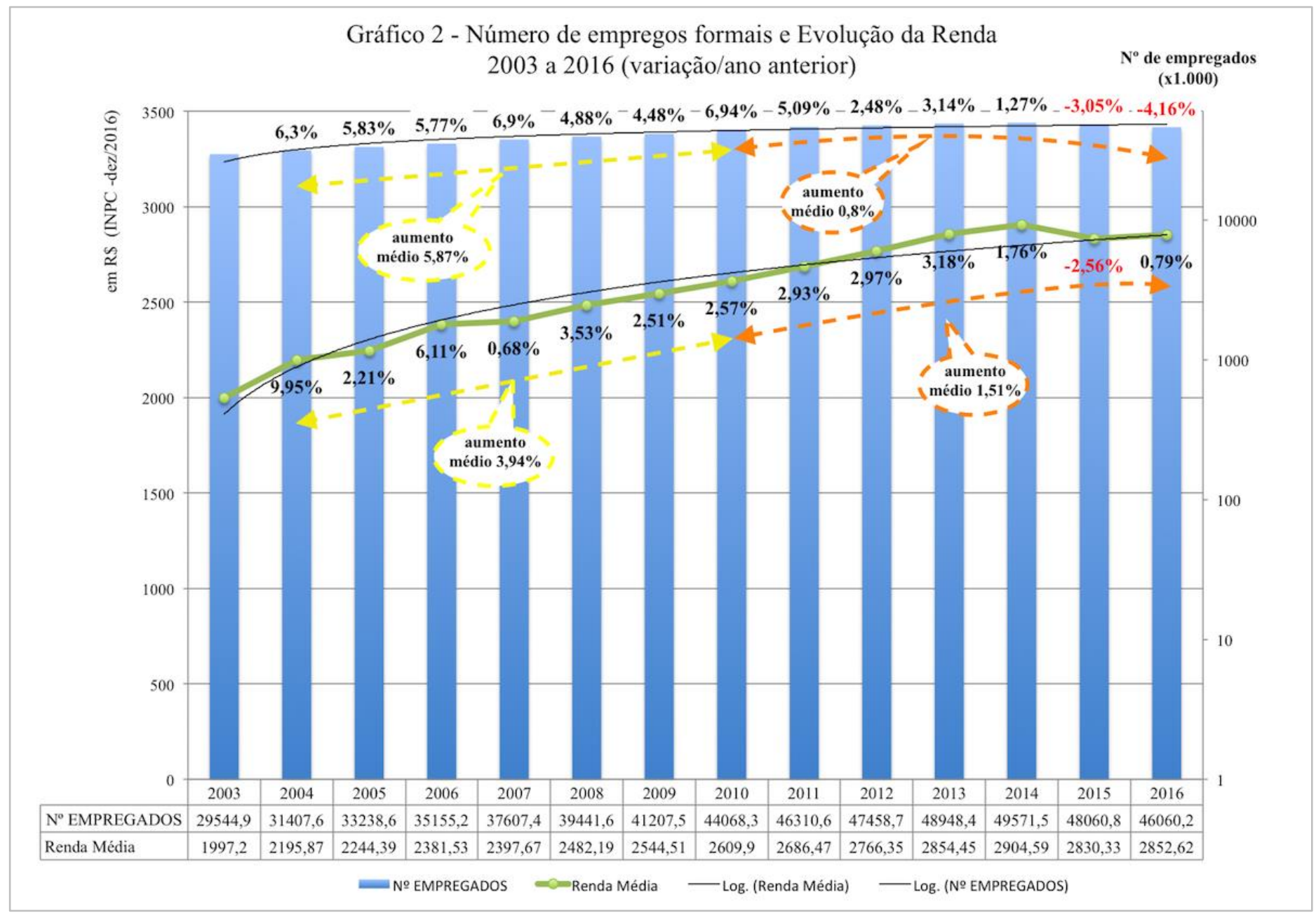

Fontes: CAGED e RAIS. Compilação própria.

No período Lula o emprego e subsidiariamente a renda estavam em patamares elevados, alcançando níveis historicamente relevantes. O ritmo da criação de postos de trabalho, refletido pelo número absoluto e relativo de empregos, é impressionante: cresce a uma média de 5,87\% ao ano no período de 2004 a 2010. Tal fenômeno na criação de postos de trabalho é acompanhado por um aumento significativo na renda que, em média, era de R\$1972,20 (2003) e chega a R\$2.609,90, aumento de 76\%, em 2010. Novamente o período Lula tem desempenho superior no que se refere à média do incremento da renda, 3,94\% no período (contra $1,51 \%$ ), bem como a média de criação de postos de trabalho, equivalente a $5,87 \%$, muito superior aos pífios $0,8 \%$ do período compreendido entre os anos de 2011 e 2016.

É essa conjugação de elementos objetivos (emprego, renda e assistência), mais toda a habilidade política (retomando novamente a definição weberiana de carisma), que fazem de Lula esse fenômeno de popularidade, refletida na já mencionada aprovação popular, o que parece firmemente correlato ao que nos diz Maquiavel que "deve, portanto, alguém que se torne príncipe mediante o apoio do povo mantê-lo como amigo, o que lhe será fácil, visto ele não lhe 
pedir senão para não ser oprimido" (Príncipe, p. 149). O povo apenas não quer ser oprimido, ao contrário da elite que deseja oprimir e lucrar através do trabalho das massas.

Contudo, a astúcia do "Príncipe da Ralé" vai muito além de prover, a partir do governo central, as condições que impactam às camadas mais vulneráveis socioeconomicamente da população brasileira. É notória sua predisposição a manter espécie de pacto (implícito ou explícito) com os poucos, especialmente ao garantir a manutenção das condições de lucros exorbitantes advindas das operações do mercado financeiro e dos bancos. A fim de apurar isto, consideramos os 50 melhores resultados positivos das instituições financeiras independentes, como se no vê Gráfico 3.

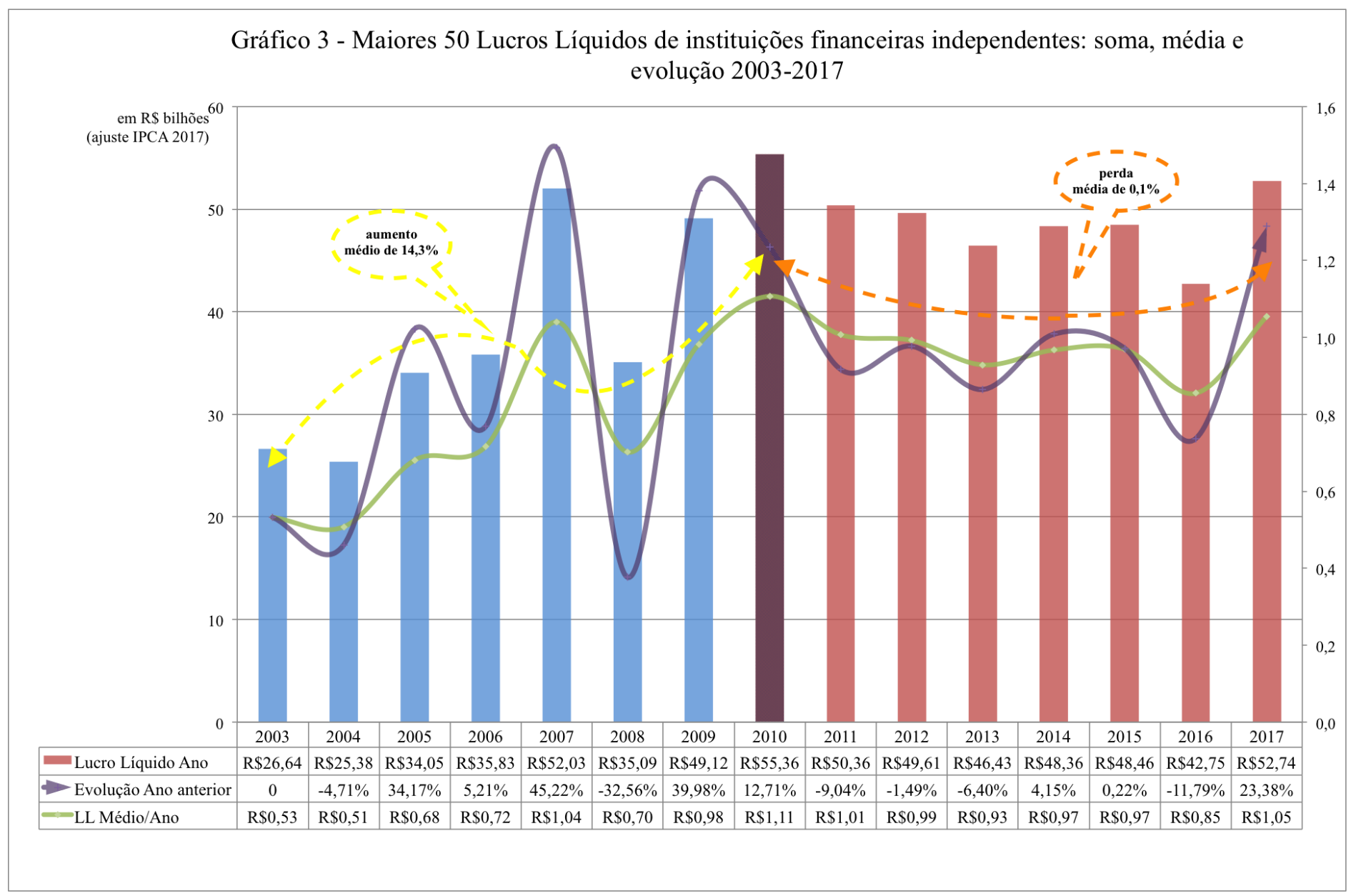

Fonte: Banco Central do Brasil, IFDATA. Compilação própria.

A evolução do desempenho das instituições financeiras durante o período Lula (2003 a 2010, em azul), apesar de menos constante que o pós-Lula (2011 a 2017), demonstra que seu governo não ameaçou os interesses dos muitos, foi mesmo o contrário. Apuramos, a partir de dados do Banco Central, que o lucro líquido total dos bancos chegou a R \$ 313,5 bilhões no acumulado do período Lula, média anual de R\$ 39,2 bilhões. Mesmo que o acumulado do período posterior tenha sido de $\mathrm{R} \$ 338,7$ bilhões, superior portanto, o maior lucro líquido (LL) 
de todo o período, na casa dos R $\$ 55$ bilhões, data de 2010, último ano do seu segundo mandato. Destaca-se ainda o desempenho médio do LL destas instituições durante os mandatos consecutivos lulistas que, mesmo considerando a grande baixa com a crise econômica em escala global de 2008, foi de $14,3 \%$, contra $-0,1 \%$ do período subsequente.

Assim, considerando esse conjunto de dados relativos às condições que o sistema financeiro, eterno protagonista no que se refere à interferência junto às ações governamentais, teve durante os o governo Lula, é razoável defender que foram garantidos os interesses de segmentos da elite local (agropecuaristas, industriários, segmentos das telecomunicações). Lula, o sagaz, promoveu verdadeira amálgama ao fundir os interesses da elite local àqueles de grupos transnacionais (a exemplo das empresas dos ramos automobilístico e de eletrodomésticos, agraciados por constantes desonerações fiscais).

Cabe ressaltar que os programas de assistência social e de combate ao déficit de moradia, especialmente o MCMV, sustentados pela ampliação dos recursos orçamentários na área, beneficiaram grupos sociais mais amplos que seus beneficiários diretos. Existem indícios da baixa qualidade dos imóveis construídos, como aponta estudo do CONOF (2017, p. 27): “no que tange à qualidade das construções, consoante sumariado no voto do Ministro Relator, em 90\% dos empreendimentos avaliados pelo TCU foram identificados vícios construtivos sistêmicos nas moradias construídas". Beneficiam-se com isso as empreiteiras definidas para a execução dos empreendimentos que certamente ampliaram suas margens de lucro ao entregarem tantos empreendimentos com problemas de diversas naturezas: "deficiências na pintura externa, deterioração precoce de pavimento, fissuras não estruturais (...), problemas em instalações hidrossanitárias, caimento inadequado dos pisos, problemas de estanqueidade de esquadrias e sua baixa qualidade" (CONOF, 2017, p. 27). Conjuntos habitacionais gigantescos localizados em bairros periféricos que já sofriam com o déficit de serviços básicos (saneamento, saúde, educação e transporte), acabam como palco de episódios frequentes de extrema violência, são alvo de contestação tanto dos moradores anteriores (que sentem o agravamento das condições previamente desfavoráveis), quanto por parte dos novos moradores (que contestam a incompatibilidade dos projetos e a baixa qualidade dos imóveis). O MCMV é manifestamente uma ação com pretensões de manter a já mencionada percepção positiva em relação ao governo, mesmo tendo notórias falhas de projeto e execução.

\section{Conclusão}

Ao analisar o contexto dos governos propostos de acordo com a ótica maquiaveliana, podemos perceber de que maneira os meandros do poder têm seus meios para atingir seus 
devidos fins. No caso do principado civil, que foi por nós especificamente estudado neste artigo, a diferenciação entre príncipes que se apoiam nos muitos e príncipes que se apoiam nos poucos tem, no Brasil recente, os seus próprios representantes.

Lula é o príncipe dos muitos por agradar o povo com seus programas de assistência social e investimento popular. Isso somado ao seu incrível carisma permitiu que ele se destacasse perante outros governantes brasileiros. Além de ser um governante positivo entre os muitos, Lula soube agradar os poucos, assegurando seus investimentos e as transações dentro do mercado financeiro. Já Temer entrou em um período conturbado do país, apoiado pelos poucos e com projetos que têm com intuito principal beneficiar o corpo empresarial e investidor. Dessa forma, seu governo peca por não levar em consideração os muitos em sua política econômica e social, beneficiando demasiadamente a elite brasileira. Isso, segundo Maquiavel é um perigo para a governabilidade do príncipe, pois aquele que não se preocupa com os muitos está fadado ao fracasso nos tempos de adversidade.

\begin{abstract}
Mas se for um príncipe que se funda no povo, que possa comandar e seja homem de coragem, que não se assuste na adversidade, que não careça da restante preparação e que tenha, com o seu ânimo e as suas ordens, animado o comum, jamais se verá enganado por ele e verificará ter lançado boas fundações. (Príncipe, p. 151)
\end{abstract}

Tomando essas palavras pelas nossas considerações finais, atentamos que um governante que queira, de fato, se manter no poder com uma boa governabilidade deve, como uma política de base, agradar o povo através de recursos sociais, pois isso não será esquecido e ele apoiará o governante quando ele assim precisar.

\title{
Maquiavelo en Brasil
}

\section{RESUMEN}

Maquiavelo al hablar del principado civil, en su obra El Príncipe, va a diferenciar entre dos tipos de posibles gobiernos: uno cuyo príncipe se apoya en los muchos (pueblo) y otro cuyo príncipe se apoya en los pocos (oligarcas). De esta forma, lo que tiene en mente es identificar los dos tipos posibles de principados civiles y demostrar que ambos logran llegar al poder si se utilizan de los medios adecuados. Este artículo pretende investigar los Gobiernos Lula y Temer bajo la óptica maquiavélica, demostrando de que manera la división de Maquiavelo podrá ser verificada en estos gobiernos a través del análisis de datos y de la evaluación de la capacidad política de los respectivos gobernantes.

PALABRAS CLAVE: Brasil. Maquiavelo. Gobierno Lula. Gobierno Temer. 


\title{
Machiavelli in Brazil
}

\begin{abstract}
Machiavelli, in his work The Prince, approaches the civil principality matter establishing two possible types of government: one whose prince rests on the many (people) and the one whose prince rests on the few (oligarchs). In this way, what he has in mind is to identify the two possible types of civil principalities and demonstrate that both can achieve power if they use the proper means. This article intends to investigate the governments Lula and Temer on Machiavellian optics, demonstrating how Machiavelli's division can be verified in these governments through data analysis and evaluating the political capacity of the respective rulers.
\end{abstract}

KEYWORDS: Brazil. Machiavelli. Lula administration. Temer administration.

\section{Referências}

BONIN, R. Popularidade de Lula bate recorde e chega a 87\%, diz Ibope. G1, 2010. Disponível em: http://g1.globo.com/politica/noticia/2010/12/popularidade-de-lula-bate-recorde-e-chega87-diz-ibope.html. Acesso em: 25/04/2018.

BRESSER-PEREIRA, L. C. A construção política brasileira. Sociedade, economia e Estado desde a Independência. São Paulo: Editora 34, 2016.

Câmara dos deputados. Orçamento da União em foco: parâmetros, resultados físcais e execução. Ano 4, n. 1. Brasília: Câmara dos Deputados, Edições Câmara, 2017.

CONOF. Estudo Técnico $N^{o}$ 12/2016. IMPACTOS DO "NOVO REGIME FISCAL". SUBSÍDIOS À ANÁLISE DA PROPOSTA DE EMENDA À CONSTITUIÇÃO - PEC N ${ }^{\circ}$ 241/2016. Brasília, p. 1-58, 2016.

CONOF. Estudo Técnico Conjunto $N^{o}$ 1/2017. Programa Minha Casa, Minha Vida: subsídios para a avaliação dos planos e orçamentos da política pública. Brasília, p. 1-31, 2017.

DAVID, G. O "teto" não pode cair sobre nossa cabeça. Le Monde Diplomatique Brasil, n. 131, p. 6-7, 2018.

FATTORELLI, M. L. A dívida pública é um mega esquema de corrupção institucionalizado (Entrevista). Carta Capital, 2015.2 Disponível em: https://www.cartacapital.com.br/economia/201ca-divida-publica-e-um-mega-esquema-decorrupcao-institucionalizado201d-9552.html. Acesso em: 24/04/2018.

FILGUEIRAS, L. A. M. A economia política do governo Lula. Rio de Janeiro: Contraponto, 2007.

GALHARDO, R. Lula: crise é tsunami nos EUA e, se chegar ao Brasil, será 'marolinha'. $O$ Globo, 2008. Disponível em: https://oglobo.globo.com/economia/lula-crise-tsunami-nos-euase-chegar-ao-brasil-sera-marolinha-3827410\#ixzz5NWWcb6GP. Acesso em: 16/08/2018.

GOMES, W. Um país repartido. Le Monde Diplomatique Brasil, 2017. Disponível em: http://diplomatique.org.br/um-pais-repartido/. Acesso em: 18/05/2017. 
IBOPE. Avaliação do Governo atinge patamar mais baixo desde que Michel Temer assumiu a Presidência, 2018. Disponível em: http://www.ibopeinteligencia.com/noticias-epesquisas/avaliacao-do-governo-atinge-patamar-mais-baixo-desde-que-michel-temerassumiu-a-presidencia/. Acesso em: 25/04/2018.

MAQUIAVEL, N. O Príncipe. Tradução de Diogo Pires Aurélio. São Paulo: Editora 34, 2017.

Ministério do trabalho e emprego. Cadastro Geral dos Empregados e Desempregados (CAGED). Disponível em: http://pdet.mte.gov.br/caged?view=default/. Acesso em 25/04/2018.

Ministério do trabalho e emprego. Relação Anual de Informações Salariais (RAIS). Disponível em: http://bi.mte.gov.br/bgcaged/caged_anuario_rais/anuario.htm/. Acesso em 25/04/2018.

SINGER, A. Cutucando onças com varas curtas. Novos Estudos, v. 102, p. 39-67, 2015.

Sistema integrado de planejamento e orçamento. Ambiente de documentação online. Disponível em: https://www1.siop.planejamento.gov.br/siopdoc/doku.php/acesso_publico:painel_orcamento/. Acesso em 26/04/2018.

STRAUSS, L. Reflexões sobre Maquiavel. Tradução e apresentação à edição brasileira de Élcio Verçosa Filho. São Paulo: É Realizações, 2015.

VAZ, F. T. Excluindo o povo do orçamento público. Le Monde Diplomatique Brasil, 2016. Disponível em: http://diplomatique.org.br/excluindo-o-povo-do-orcamento-publico/. Acesso em 24/04/2018.

VIROLI, M. O Sorriso de Nicolau. História de Maquiavel. Tradução de Valéria Pereira da Silva. São Paulo: Estação Liberdade, 2002.

WEBER, M. Ciência e Política: duas vocações. Tradução de Leonidas Hegenberg e Octany Silveira da Mota. São Paulo: Cultrix, 2011.

\section{Sobre os autores}

Luiz Maurício Bentim da Rocha Menezes possui doutorado pelo Programa de Pós-Graduação em Lógica e Metafísica da Universidade Federal do Rio de Janeiro (PPGLM/UFRJ - 2017), mestrado pelo PPGLM/UFRJ (2011), graduação em Filosofia pela Universidade Federal do Rio de Janeiro (Bacharelado e Licenciatura - 2010) e graduação em Comunicação Social Faculdades Integradas Hélio Alonso (2006). Tem experiência nas áreas de Filosofia com ênfase em Ética, Filosofia Política e Metafísica. Atualmente é professor efetivo de filosofia do Instituto Federal do Triângulo Mineiro (IFTM). Endereço eletrônico: lmbrmenezes@ yahoo.com.br

Gabriel Medeiros Chati é professor do Bacharelado em Produção e Política Cultural da Universidade Federal do Pampa câmpus Jaguarão. Doutorando em Ciência Política pela Universidade Federal de Pelotas (2016). Mestre em Patrimônio Cultural e Sociedade pela Universidade da Região de Joinville (2012). Bacharel em Produção Cultural pela Universidade Federal Fluminense (2007). Consultor Ad Hoc Sênior do Fundo de Apoio à Cultura do Distrito 
Federal (FAC/DF; 2011-2018). Avaliador do Fundo Municipal de Incentivo à Cultura de Joinville/SC na área de Patrimônio Cultural Material (2017). Analista Técnico do Projeto de Assistência Técnica à elaboração de Planos Municipais de Cultura (UFBA), financiado pelo Ministério da Cultura (2012). Endereço eletrônico: gabrielchati@id.uff.br 